\title{
A New Class acg-set Weaker Form of Closed Sets in Topological Spaces
}

\author{
A. Pushpalatha \\ Department of Mathematics, \\ Government Arts College \\ Udumalpet-642126, Tirupur District \\ Tamilnadu, India
}

\author{
A. Kavitha \\ Department of Mathematics \\ Vidyasagar College of Arts and Science \\ Udumalpet-642126, Tirupur District \\ Tamilnadu, India
}

\begin{abstract}
In this paper, a new class acg-closed sets, as weaker forms of closed sets in topological spaces are introduced. Some of its properties are studied. Also we have provided continuity ,closed map and open map are also introduced .
\end{abstract}

\section{Keywords}

acg-closed, $\alpha c g$ - continuous functions, $\alpha c g$ closed map, acg open map.

\section{AMS SUBJECT CLASSIFICATION (2000): \\ 54A40, 03F55}

\section{INTRODUCTION}

In 1970, Levine [1] first considered the concept of generalized closed (briefly,g-closed) sets were defined and investigated. Tong [8] and Hatir E [4] introduced B-sets and t-sets and $\alpha^{*}$ sets respectively. t-sets and $\alpha^{*}$-sets are weak forms of open sets. In this paper, we have introduced a new class of sets called acg-closed sets and study some of their properties. Noiri,[21] introduced $\alpha$-continuous functions. Sundaram [6] introduced the concept of generalized continuous function includes the class of continuous functions and studies several properties related to it. In this section, we introduce the concepts of acg-continuous function in topological spaces and study some of their properties. It is an extension study of [20]for continuous functions, closed and open maps.

\section{PRELIMINARIES}

Definition: 2.1 A subset $\mathrm{A}$ of a topological $\operatorname{space}(\mathrm{X}, \tau)$ is called

(i)Generalized closed (g-closed)[1] if $\operatorname{cl}(\mathrm{A}) \subseteq \mathrm{U}$ whenever

$\mathrm{A} \subseteq \mathrm{U}$, and $\mathrm{U}$ is open in $\mathrm{X}$.

(ii)Semi-generalized closed(sg-closed)[9] if $\operatorname{scl}(\mathrm{A}) \subseteq \mathrm{U}$ whenever $\mathrm{A} \subseteq \mathrm{U}$, and $\mathrm{U}$ is semi open in $\mathrm{X}$.

(iii)Generalized semi preclosed [12] if $\operatorname{spcl}(\mathrm{A}) \subseteq \mathrm{U}$ whenever $\mathrm{A} \subseteq \mathrm{U}$, and $\mathrm{U}$ is open in $\mathrm{X}$.

(iv)Weakly generalized closed[10] if $\operatorname{cl}(\operatorname{int}(\mathrm{A})) \subseteq \mathrm{U}$ whenever $\mathrm{A} \subseteq \mathrm{U}$, and $\mathrm{U}$ is open in $\mathrm{X}$.

(v) $\alpha$-generalized closed $\alpha$ g-closed[15] if $\alpha \operatorname{cl}(\mathrm{A}) \subseteq \mathrm{U}$ whenever $\mathrm{A} \subseteq \mathrm{U}$, and $\mathrm{U}$ is open in $\mathrm{X}$.

Definition: 2.2 A subset $\mathrm{S}$ of $\mathrm{X}$ is called

(i) semiopen [1] if there exists an open set $\mathrm{G}$ such that $\mathrm{G} \subseteq \mathrm{S}$ $\subseteq \mathrm{cl}(\mathrm{G})$ and semi closed[13] if there exists a closed set $\mathrm{F}$ such that int $(\mathrm{F}) \subseteq \mathrm{S} \subseteq \mathrm{F}$. (ii) $\alpha$-open[16] if $S \subseteq \operatorname{int}(\operatorname{cl}(\operatorname{int}(S)))$ and $\alpha$-closed if $S \supseteq$ $\operatorname{cl}(\operatorname{int}(\operatorname{cl}(\mathrm{S})))$.

Result: $2.3 \quad$ (i) $\alpha \mathrm{cl}(\mathrm{S})=\mathrm{S} \cup \operatorname{cl}(\operatorname{cl}(\operatorname{int}(\operatorname{cl}(\mathrm{S})))[14]$

(ii) $\alpha \operatorname{int}(\mathrm{S})=\mathrm{S} \cap \operatorname{int}(\operatorname{cl}(\operatorname{int}(\mathrm{S})))[11]$.

(iii) In this work, we use the notations $\mathrm{C}(\mathrm{S})$ sets for C-sets (Due to Sundaram)[7].

Definition: 2.4 For a subset $\mathrm{A}$ of $\mathrm{X}$ is called

(a) a t-set in $X[8]$ if $\operatorname{int}(A)=\operatorname{int}(\operatorname{cl}(\mathrm{A}))$.

(b) a B-set in $\mathrm{X}[8]$ if $\mathrm{A}=\mathrm{G} \cap \mathrm{F}$ where $\mathrm{G}$ is open and $\mathrm{F}$ is a $\mathrm{t}$-set in $\mathrm{X}$.

(c) an $\alpha^{*}$-set in $\mathrm{X}[4]$ if $\operatorname{int}(\mathrm{A})=\operatorname{int}(\mathrm{cl}(\operatorname{int}(\mathrm{A})))$.

(d) a C-set(Due to Sundaram)[7] if $A=G \cap F$ where $G$ is gopen and $\mathrm{F}$ is a t-set in $\mathrm{X}$.

(e) a C-set (Due to Hatir, Noiri and Yuksel)[4] if $\mathrm{A}=\mathrm{G} \cap \mathrm{F}$ where $\mathrm{G}$ is open and $\mathrm{F}$ is an $\alpha^{*}$-set in $\mathrm{X}$.

(f) a $\mathrm{C}^{*}$ set[5] if $\mathrm{A}=\mathrm{G} \cap \mathrm{F}$ where $\mathrm{G}$ is g-open and $\mathrm{F}$ is an $\alpha^{*}$-set in $\mathrm{X}$.

Definition: 2.5 A map f: $\mathrm{X} \rightarrow \mathrm{Y}$ is called

(a) semicontinuous[1] if $\mathrm{f}^{-1}(\mathrm{~F})$ is semiclosed in $\mathrm{X}$ for each closed set $\mathrm{F}$ in $\mathrm{Y}$,

(b) generalized continuous (g-continuous)[17] if $\mathrm{f}^{-1}(\mathrm{~F})$ is

(c) g-closed in $\mathrm{X}$ for each closed set $\mathrm{F}$ in $\mathrm{Y}$,

(d) $\alpha$-generalized continuous ( $\alpha$ g-continuous) $[18]$ if $\mathrm{f}^{-1}(\mathrm{~F})$ is $\alpha \mathrm{g}$-closed in $\mathrm{X}$ for each closed set $\mathrm{F}$ in $\mathrm{Y}$,

(e) generalized semicontinuous (gs-continuous)[6] if $\mathrm{f}^{-1}(\mathrm{~F})$ is gs-closed in $\mathrm{X}$ for each closed set $\mathrm{F}$ in $\mathrm{Y}$,

(f) $\alpha$-continuous [19] if $\mathrm{f}^{-1}(\mathrm{~F})$ is $\alpha$-open in $\mathrm{X}$ for each open set $\mathrm{F}$ in $\mathrm{Y}$.

(g) closed map if for each closed set $F$ in $\mathrm{X}, \mathrm{f}(\mathrm{F})$ is closed in Y.

(h) open map if for each open set $\mathrm{F}$ in $\mathrm{X}, \mathrm{f}(\mathrm{F})$ is open in $\mathrm{Y}$.

\section{3. acg-SET IN TOPOLOGICAL SPACES}

Definition:3.1 A subset A of $X$ is called $\alpha$ cg- set if $\alpha c 1(A)$ $\subseteq \mathrm{U}$ whenever $\mathrm{A} \subseteq \mathrm{U}$ and $\mathrm{U}$ is $\mathrm{C}$-set.

Remark:3.2 i) The complement of $\alpha \mathrm{cg}$ - set is called $\alpha \mathrm{cg}$ open set.

Theorem:3.3 Every closed set in $\mathrm{X}$ is $\alpha \mathrm{cg}$ - set in $\mathrm{X}$ but not conversely. 
Proof: Let $\mathrm{A}$ be a closed set in $\mathrm{X}$. Let $\mathrm{U}$ be a $\mathrm{C}$-set such that $\mathrm{A} \subseteq \mathrm{U}$. Since $\mathrm{A}$ is closed, $\operatorname{cl}(\mathrm{A})=\mathrm{A}$, therefore $\operatorname{cl}(\mathrm{A}) \subseteq \mathrm{U}$. But $\alpha \mathrm{cl}(\mathrm{A}) \subseteq \operatorname{cl}(\mathrm{A}) \subseteq \mathrm{A} \subseteq \mathrm{U}$. Therefore $\alpha \mathrm{cl}(\mathrm{A}) \subseteq \mathrm{U}$. Hence A is $\alpha c g$ set in $\mathrm{X}$.

The converse of the theorem 3.3 need not be true as seen from the following example.

Example:3.4 Consider the topological space $X=\{a, b, c\}$ with the topology $\tau=\{\phi, X,\{b\},\{c\},\{b, c\}\}$. The sets $\{b, c\}$ is $\alpha \mathrm{cg}$ set in $\mathrm{X}$, but not closed in $\mathrm{X}$.

Theorem:3.5 The union of two $\alpha$ cg- sets is $\alpha \mathrm{cg}$-set in $\mathrm{X}$.

Proof: Let $\mathrm{A}$ and $\mathrm{B}$ are $\alpha c g-$ set in $\mathrm{X}$. Let $\mathrm{U}$ be an $\alpha c \mathrm{cg}$ in $\mathrm{X}$ such that $A \cup B \subseteq U$ then $A \subseteq U, B \subseteq U$. SinceA and $\mathrm{B}$ are $\quad \alpha c g$-sets then $\alpha \operatorname{cl}(\mathrm{A}) \subseteq \mathrm{U}, \quad \alpha c \mathrm{~B}(\mathrm{~B}) \subseteq \mathrm{U}$. Hence $\alpha \operatorname{cl}(A \cup B)=\alpha \operatorname{cl}(A) \cup \alpha c l(B) \subseteq U$. Therefore AUB is acg- set in $\mathrm{X}$.

Theorem:3.6 Every g-closed set in $\mathrm{X}$ is $\alpha$ cg- set in $\mathrm{X}$ but not conversely.

Proof: Let A be g-closed set in X. Let U be a C- set in X such that $\mathrm{A} \subseteq \mathrm{U}$. To prove $\alpha \mathrm{cl}(\mathrm{A}) \subseteq \mathrm{U}$. Since $\mathrm{U}$ is $\mathrm{C}$-set, $\mathrm{U}=\mathrm{P} \cap \mathrm{Q}$ where $\mathrm{P}$ is open, $\mathrm{Q}$ is $\alpha^{*}$ set. Therefore $\mathrm{U} \subseteq \mathrm{P}, \mathrm{U} \subseteq \mathrm{Q}$. Therefore $\mathrm{A} \subseteq \mathrm{U} \subseteq \mathrm{P}$ implies $\mathrm{A} \subseteq \mathrm{P}, \mathrm{P}$ is open since $\mathrm{A}$ is $\mathrm{g}$ closed implies $\operatorname{cl}(\mathrm{A}) \subseteq \mathrm{P}$. Since $\alpha \operatorname{cl}(A) \subseteq \operatorname{cl}(A) \subseteq U \subseteq P$ .That is $\alpha \mathrm{cl}(\mathrm{A}) \subseteq \mathrm{U}$.

The converse of the theorem 3.6 need not be true as seen from the following example

Example:3.7 Consider the topological space $X=\{a, b, c\}$ with the topology $\tau=\{\phi, X,\{a\}\}$. The set $\{\mathrm{a}\}$ is $\alpha$ cg-set in $\mathrm{X}$, but not $\mathrm{g}$-closed in $\mathrm{X}$.

Theorem:3.8 Every $\alpha$ g-closed set in $\mathrm{X}$ is $\alpha$ cg- set in $\mathrm{X}$ but not conversely.

Proof: Let A be $\alpha$-closed. Let $\mathrm{U}$ be a C- set in X such that $\mathrm{A} \subseteq \mathrm{U}$. To prove $\alpha \mathrm{cl}(\mathrm{A}) \subseteq \mathrm{U}$. Since $\mathrm{U}$ is $\mathrm{C}$-set, $\mathrm{U}=\mathrm{P} \cap \mathrm{Q}$ where $\mathrm{P}$ is open, $\mathrm{Q}$ is $\alpha^{*}$ set. Therefore $\mathrm{U} \subseteq \mathrm{P}, \quad \mathrm{U}$ $\subseteq$ Q.Since $\mathrm{A} \subseteq \mathrm{U} \subseteq \mathrm{P}$ implies $\mathrm{A} \subseteq \mathrm{P}, \mathrm{P}$ is open since $\mathrm{A}$ is $\alpha$ g-closed implies $\operatorname{cl}(\mathrm{A}) \subseteq \mathrm{P}$. Since $\alpha \operatorname{cl}(A) \subseteq \operatorname{cl}(A) \subseteq U \subseteq P$. That is $\alpha \operatorname{cl}(\mathrm{A}) \subseteq \mathrm{U}$.

The converse of the theorem 3.8 need not be true as seen from the following example

Example:3.9 Consider the topological space $X=\{a, b, c\}$ with the topology $\tau=\{\phi, X,\{a\},\{b\},\{a, b\}\}$. The sets $\{a, b\}$ is $\alpha c g$ set in $X$, but not $\alpha$ g-closed in $X$.

Theorem:3.10 Every gs-closed set in $\mathrm{X}$ is $\alpha$ cg- set in $\mathrm{X}$ but not conversely.

Proof: Let A be gs-closed. Let U be a C- set in X such that A $\subseteq \mathrm{U}$. To prove $\alpha \mathrm{cl}(\mathrm{A}) \subseteq \mathrm{U}$. Since $\mathrm{U}$ is $\mathrm{C}$-set, $\mathrm{U}=\mathrm{P} \cap \mathrm{Q}$ where $\mathrm{P}$ is open, $\mathrm{Q}$ is $\alpha^{*}$ set. Therefore $\mathrm{U} \subseteq \mathrm{P}, \mathrm{U} \subseteq \mathrm{Q}$. Since $\mathrm{A} \subseteq \mathrm{U}$ $\subseteq \mathrm{P}$ implies $\mathrm{A} \subseteq \mathrm{P}, \mathrm{P}$ is open.Since $\mathrm{A}$ is gs-closed implies $\operatorname{cl}(\mathrm{A}) \subseteq \mathrm{P}$. Since $s c l(A) \subseteq \operatorname{cl}(A) \subseteq U \subseteq P, \operatorname{acl}(\mathrm{A})$ $\subseteq \mathrm{cl}(\mathrm{A}) \subseteq \mathrm{U} \subseteq \mathrm{P}$. That is $\alpha \mathrm{cl}(\mathrm{A}) \subseteq \mathrm{U}$.

The converse of the theorem 3.10 need not be true as seen from the following example
Example:3.11 Consider the topological space $X=\{a, b, c\}$ with the topology $\tau=\{\phi, X,\{a\},\{b\},\{a, b\}\}$. The sets $\{a, b\}$ is $\alpha \mathrm{cg}$ set in $X$, but not gs-closed in X.

Theorem:3.12 Every $\alpha$-closed set in $\mathrm{X}$ is $\alpha$ cg- set in $\mathrm{X}$ but not conversely.

Proof: Let A be $\alpha$-closed. Let U be a C- set in X such that A $\subseteq \mathrm{U}$. To prove $\alpha \mathrm{cl}(\mathrm{A}) \subseteq \mathrm{U}$. Since $\mathrm{A}$ is $\alpha$ closed set $\operatorname{cl}(\operatorname{int}(\operatorname{cl}(\mathrm{A}))) \subseteq \mathrm{U}$ implies $A \cup \operatorname{cl}(\operatorname{int}(\operatorname{cl}(A))) \subseteq U$. That is $\alpha \mathrm{cl}(\mathrm{A}) \subseteq \mathrm{U}$

The converse of the theorem 3.12 need not be true as seen from the following example

Example:3.13 Consider the topological space $X=\{a, b, c\}$ with the topology $\tau=\{\phi, X,\{a\},\{b\},\{a, b\}\}$. The sets $\{a, b\}$ is $\alpha c g$ set in X,but not $\alpha$-closed in X.

We illustrate the relations between various sets in the following diagram Fig 3.1.

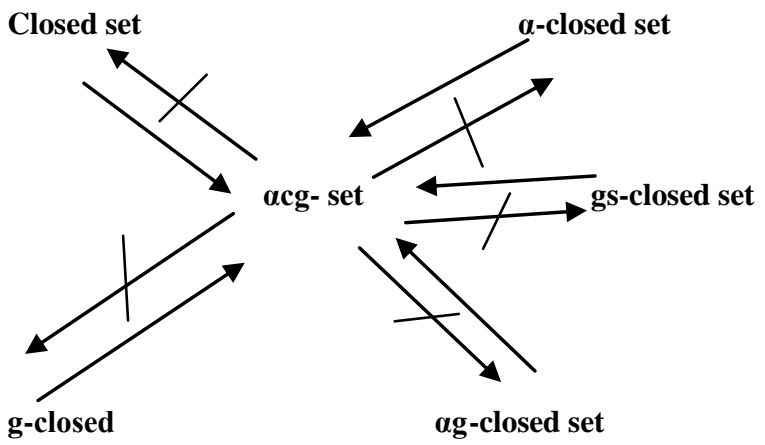

Fig:3.1

In the above diagram Fig 3.1 none of the implications can be reversed.

Remark:3.14 The concept of $\alpha c g$ - set is independent of the following classes of sets namely semiclosed sets, $\beta$-closed, weakly g-closed.

Example:3.15 Consider the topological space $X=\{a, b, c\}$ with topology $\tau=\{\phi, X,\{b\},\{c\},\{b, c\}\}$. In this space, the sets $\{b\},\{c\}$ are $\beta$-closed,weakly g-closed in $X$, but not $\alpha c g$ sets in $X$. The $\{b, c\}$ is acg set but not $\beta$-closed, weakly g-closed in $\mathrm{X}$.

Example:3.16 Consider the topological space $X=\{a, b, c\}$ with topology $\tau=\{\phi, X,\{b\},\{c\},\{b, c\}\}$. In this space, the sets $\{b\},\{c\}$ are semiclosed but not $\alpha \mathrm{cg}$ sets and $\{a\}$ is $\alpha \mathrm{cg}$ sets but not semiclosed set in $\mathrm{X}$.

From above theorem and example. We get the following diagram Fig 3.2 with

$\beta$-closed

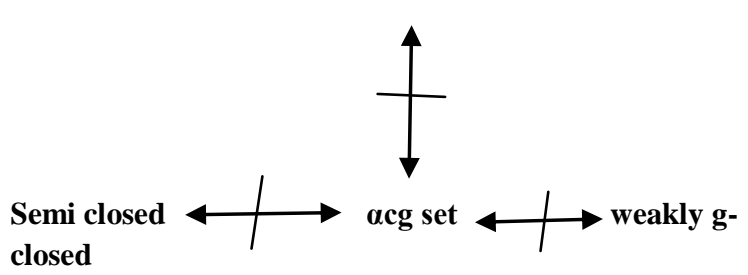

Fig 3.2 


\section{4. acg CONTINUOUS MAPPINGS TOPOLOGICAL SPACES}

In this section we introduce acg continuous mappings.

Definition:4 A map $\mathrm{f} ; \mathrm{X} \rightarrow \mathrm{Y}$ from topological space $\mathrm{X}$ into a topological space $\mathrm{Y}$ is called acg continuous if its inverse image of every closed in $\mathrm{Y}$ is $\alpha \mathrm{cg}$ closed in $\mathrm{X}$.

Theorem:4.0 If a map $f: X \rightarrow Y$ is continuous then it is $\alpha \mathrm{cg}$ continuous but not conversely.

Proof: Let $f: X \rightarrow Y$ be continuous. Let $F$ be any closed set in $Y$. Then the inverse image $f^{-1}[F]$ is closed in Y. Since every closed set is acg closed set, $f^{-1}[F]$ is acg closed in $\mathrm{X}$. Therefore $\mathrm{f}$ is acg continuous.

The converse of the theorem 4.0 need not be true as seen from the following example

Example:4.1 Let $\mathrm{X}=\mathrm{Y}=\{\mathrm{a}, \mathrm{b}, \mathrm{c}\}, \tau=\{\phi, \mathrm{X},\{\mathrm{b}\},\{\mathrm{c}\},\{\mathrm{b}, \mathrm{c}\}\}$, $\sigma=\{\phi, Y,\{a\}\}$. Let $f:(X, \tau) \rightarrow(Y, \sigma)$ be the identity map. Then $\mathrm{f}$ is $\alpha \mathrm{cg}$ continuous but not continuous, since for the closed set $\{b, c\}$ in $Y, f^{-1}(\{b, c\})=\{b, c\}$ is not closed in $X$, Therefore $\mathrm{f}$ is not continuous.

Theorem:4.2 If a map $\mathrm{f}: \mathrm{X} \rightarrow \mathrm{Y}$ is g-continuous then it is $\alpha \mathrm{cg}$ continuous but not conversely.

Proof: Let $\mathrm{f}: \mathrm{X} \rightarrow \mathrm{Y}$ be g-continuous. Let $\mathrm{F}$ be any g-closed set in $Y$. Then the inverse image $f^{-1}[F]$ is g-closed in Y. Since every g-closed set is $\alpha$ cg closed set, $f^{-1}[F]$ is $\alpha$ cg closed set in $\mathrm{X}$. Therefore $\mathrm{f}$ is $\alpha \mathrm{cg}$ continuous.

The converse of the theorem 4.2 need not be true as seen from the following example

Example:4.3 Let $\mathrm{X}=\mathrm{Y}=\{\mathrm{a}, \mathrm{b}, \mathrm{c}\} \quad, \quad \tau=\{\phi, X,\{\mathrm{a}\}\}$, $\sigma=\{\phi, Y,\{b, c\}\}$. Let $f:(X, \tau) \rightarrow(Y, \sigma)$ be the identity map. Then $\mathrm{f}$ is acg continuous but not $\mathrm{g}$-continuous since for the closed set $\{a\}$ in $Y, f^{-1}(\{a\})=\{a\}$ is not g-closed in $\mathrm{X}$.Therefore $\mathrm{f}$ is not g-continuous.

Theorem:4.4 If a map $\mathrm{f}: \mathrm{X} \rightarrow \mathrm{Y}$ is $\alpha \mathrm{g}$-continuous then it is $\alpha \mathrm{cg}$ continuous but not conversely.

Proof: Let $\mathrm{f}: \mathrm{X} \rightarrow \mathrm{Y}$ be $\alpha \mathrm{g}$-continuous. Let $\mathrm{F}$ be any $\alpha \mathrm{g}$-closed set in $\mathrm{Y}$. Then the inverse image $\mathrm{f}^{-1}[\mathrm{~F}]$ is $\alpha$ g-closed in $\mathrm{Y}$. Since every $\alpha \mathrm{g}$-closed set is $\alpha \mathrm{cg}$ closed set, $f^{-1}[F]$ is $\alpha \mathrm{cg}$ closed set in X. Therefore $\mathrm{f}$ is $\alpha \mathrm{cg}$ continuous.

The converse of the theorem 4.4 need not be true as seen from the following example.

Example:4.5 Let $\mathrm{X}=\mathrm{Y}=\{\mathrm{a}, \mathrm{b}, \mathrm{c}\}, \tau=\{\phi, X,\{\mathrm{a}\},\{\mathrm{b}\},\{\mathrm{a}, \mathrm{b}\}\}$, $\sigma=\{\phi, Y,\{c\}\}$. Let $f:(X, \tau) \rightarrow(Y, \sigma)$ be the identity map. Then $\mathrm{f}$ is $\alpha \mathrm{cg}$ continuous but not $\alpha \mathrm{g}$-continuous since for the closed set $\{a, b\}$ in $Y, \mathrm{f}^{-1}(\{a, b\})=\{a, b\}$ is not $\alpha \mathrm{g}$-closed in $\mathrm{X}$. Therefore $\mathrm{f}$ is not $\alpha \mathrm{g}$-continuous.

Theorem:4.6 If a map $\mathrm{f}: \mathrm{X} \rightarrow \mathrm{Y}$ is $\alpha$-continuous then it is $\alpha \mathrm{cg}$ continuous but not conversely.

Proof: Let $\mathrm{f}: \mathrm{X} \rightarrow \mathrm{Y}$ be $\alpha$-continuous. Let $\mathrm{F}$ be any $\alpha$-closed set in $\mathrm{Y}$. Then the inverse image $\mathrm{f}^{-1}[\mathrm{~F}]$ is $\alpha$-closed in $\mathrm{Y}$. Since every aclosed set is $\alpha c g$ closed set, $f^{-1}[F]$ is $\alpha c g$ closed set in $\mathrm{X}$. Therefore $\mathrm{f}$ is $\alpha \mathrm{cg}$ continuous.

The converse of the theorem 4.6 need not be true as seen from the following example.
Example:4.7 Let $\mathrm{X}=\mathrm{Y}=\{\mathrm{a}, \mathrm{b}, \mathrm{c}\} \quad, \tau=\{\phi, \mathrm{X},\{\mathrm{a}\},\{\mathrm{b}\},\{\mathrm{a}, \mathrm{b}\}\}$, $\sigma=\{\phi, Y,\{\mathrm{c}\}\}$. Let $f:(X, \tau) \rightarrow(Y, \sigma)$ be the identity map. Then $\mathrm{f}$ is $\alpha \mathrm{cg}$ continuous but not $\alpha$-continuous since for the closed set $\{a, b\}$ in $Y, f^{-1}(\{a, b\})=\{a, b\}$ is not $\alpha$-closed in $\mathrm{X}$.Therefore $\mathrm{f}$ is not $\alpha$-continuous

Theorem:4.8 If a map $\mathrm{f}: \mathrm{X} \rightarrow \mathrm{Y}$ is gs-continuous then it is acg continuous but not conversely.

Proof: Let $\mathrm{f}: \mathrm{X} \rightarrow \mathrm{Y}$ be gs-continuous. Let $\mathrm{F}$ be any gs-closed set in $Y$. Then the inverse image $f^{-1}[F]$ is

gs-closed in Y. Since every gs-closed set is acg closed set, $f^{-1}[F]$ is $\alpha c g$ closed set.. Therefore $\mathrm{f}$ is $\alpha \mathrm{cg}$ continuous.

The converse of the theorem 4.8 need not be true as seen from the following example.

Example:4.9 Let $\mathrm{X}=\mathrm{Y}=\{\mathrm{a}, \mathrm{b}, \mathrm{c}\} \quad, \quad \tau=\{\phi, \mathrm{X},\{\mathrm{c}\}\}$, $\sigma=\{\phi, Y,\{a\},\{b\},\{a, b\}\}$. Let $f:(X, \tau) \rightarrow(Y, \sigma)$ be the identity map. Then $\mathrm{f}$ is $\alpha \mathrm{cg}$ continuous but not gs-continuous since for the closed set $\{c\}$ in $Y, f^{-1}(\{c\})=\{c\}$ is not gs-closed in $X$.

We illustrate the relations between various generalizations of continuous functions in the following diagram Fig 4.1.

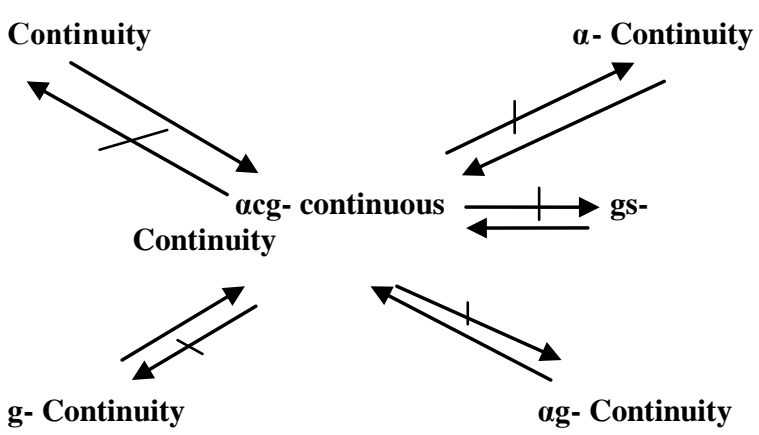

Fig 4.1

In the above diagram Fig 4.1 none of the implications can be reversed.

\section{5. $\alpha c g-C L O S E D$ MAPS AND $\alpha c g-O P E N$ MAPS IN TOPOLOGICAL SPACES}

Malghan [22] introduced and investigated some properties of generalized closed maps in topological spaces. The concept of generalized open map was introduced by Sundaram [6]. Biswas [23]defined semi open mappings as a generalization of open mappings and studied several of its properties.

In this section, we introduced the concepts of acgclosed maps and acg -open maps in topological spaces.

Definition :5.1 A map $\mathrm{f}: \mathrm{X} \rightarrow \mathrm{Y}$ is called $\alpha \mathrm{cg}$-closed map if for each closed set $\mathrm{F}$ in $\mathrm{X}, \mathrm{f}(\mathrm{F})$ is a acg -closed set in $\mathrm{Y}$.

Theorem : 5.2 If $\mathrm{f}: \mathrm{X} \rightarrow \mathrm{Y}$ is a closed map, then it is acg-closed but not conversely.

Proof : Since every closed set is acg -closed the result follows.

The converse of the above theorem need not be true as seen from the following example. 
Example : 5.3 Consider the topological spaces $\mathrm{X}=\mathrm{Y}=\{\mathrm{a}, \mathrm{b}, \mathrm{c}\}$ with topologies $\tau=\{\varphi, \mathrm{X},\{\mathrm{a}\},\{\mathrm{b}\},\{\mathrm{a}, \mathrm{b}\}\}$ and $\sigma=\{\varphi, \mathrm{Y},\{\mathrm{a}$, b $\}$. Here $C(X, \tau)=\{\varphi, X,\{b, c\},\{a, c\},\{c\}\}$, $\mathrm{C}(\mathrm{Y}, \sigma)=\{\varphi, \mathrm{Y},\{\mathrm{c}\}\}$ and $\alpha \mathrm{cg}-(\mathrm{Y}, \sigma)=\mathrm{P}(\mathrm{X})$. Let $\mathrm{f}$ be the identity map from $\mathrm{X}$ onto $\mathrm{Y}$. Then

$\mathrm{f}$ is acg -closed but not a closed map, since for the closed set $\{b, c\}$ in $(X, \tau), f(\{b, c\})=\{b, c\}$ is not a closed set in $Y$.

Definition : 5.4 A map $\mathrm{f}: \mathrm{X} \rightarrow \mathrm{Y}$ is called a $\alpha \mathrm{cg}$-open map if $f(U)$ is $\alpha c g$-open in $Y$ for every open set $U$ in $X$.

Theorem : 5.5 If $\mathrm{f}: \mathrm{X} \rightarrow \mathrm{Y}$ is an open map, then it is $\alpha \mathrm{cg}$ open but not conversely.

Proof : Let $f: X \rightarrow Y$ be an open map. Let $U$ be any open set in $X$. Then $f(U)$ is an open set in $Y$. Then $f(U)$ is $\alpha$ cg -open, since every open set is $\alpha c g$-open. Therefore $\mathrm{f}$ is $\alpha \mathrm{cg}$-open.

The converse of the above theorem need not be true as seen from the following example.

Example : 5.6 Consider the topological spaces $X=Y=\{a, b, c\}$ with topologies $\tau=\{\varphi, \mathrm{X},\{\mathrm{a}\},\{\mathrm{b}\},\{\mathrm{a}, \mathrm{b}\}\}$ and $\sigma=\{\varphi, \mathrm{Y},\{\mathrm{a}$, $\mathrm{b}\}$ \}. Here $\alpha \operatorname{cgo}-(\mathrm{Y}, \sigma)=\mathrm{P}(\mathrm{X})$. Then the identity function $\mathrm{f}$ : $\mathrm{X} \rightarrow \mathrm{Y}$ is $\alpha \mathrm{cg}$-open but not open, since for the open set $\{\mathrm{a}\}$ in $(\mathrm{X}, \tau), \mathrm{f}(\{\mathrm{a}\})=\{\mathrm{a}\}$ is $\alpha \mathrm{cg}$ open but not open in (Y, $\sigma)$. Therefore $\mathrm{f}$ is not an open map.

Theorem : 5.7 A map $\mathrm{f}: \mathrm{X} \rightarrow \mathrm{Y}$ is $\alpha \mathrm{cg}$-closed iff for each subset $\mathrm{S}$ of $\mathrm{Y}$ and for each open set $\mathrm{U}$ containing $\mathrm{f}^{-1}(\mathrm{~S})$ there is a $\alpha c g$-open set $\mathrm{V}$ of $\mathrm{Y}$ such that $\mathrm{S} \subseteq \mathrm{V}$ and $\mathrm{f}^{-1}(\mathrm{~V}) \subseteq \mathrm{U}$.

Proof : Suppose $\mathrm{f}$ is $\alpha \mathrm{cg}$-closed. Let $\mathrm{S}$ be a subset of $\mathrm{Y}$ and $\mathrm{U}$ is an open set of $\mathrm{X}$ such that

$\mathrm{f}^{-1}(\mathrm{~S}) \subseteq \mathrm{U}$. Then $\mathrm{V}=\mathrm{Y}-\mathrm{f}(\mathrm{X}-\mathrm{U})$ is a $\alpha \mathrm{cg}$-open set containing S such that $\mathrm{f}^{-1}(\mathrm{~V}) \subseteq \mathrm{U}$.

Conversely, suppose that $\mathrm{F}$ is a closed set in $\mathrm{X}$. Then

$\mathrm{f}^{-1}(\mathrm{Y}-\mathrm{f}(\mathrm{F}))=\mathrm{X}-\mathrm{F}$ and $\mathrm{X}-\mathrm{F}$ is open. By hypothesis, there is a $\alpha$ cg -open set $\mathrm{V}$ of $\mathrm{Y}$ such that $\mathrm{Y}-\mathrm{f}(\mathrm{F}) \subseteq \mathrm{V}$ and

$\mathrm{f}^{-1}(\mathrm{~V}) \subseteq \mathrm{X}-\mathrm{F}$. Therefore $\mathrm{F} \subseteq \mathrm{X}-\mathrm{f}^{-1}(\mathrm{~V})$. Hence

$\mathrm{Y}-\mathrm{V} \subseteq \mathrm{f}(\mathrm{F}) \subseteq \mathrm{f}\left(\mathrm{X}-\mathrm{f}^{-1}(\mathrm{~V})\right) \subseteq \mathrm{Y}-\mathrm{V}$, which implies

$f(F)=Y-V$. Since $Y-V$ is $\alpha c g$-closed and thus $f$ is $\alpha c g-$ closed map.

Theorem : 5.8 If $\mathrm{f}: \mathrm{X} \rightarrow \mathrm{Y}$ is g-continuous and $\alpha \mathrm{cg}$-closed and $A$ is a $\alpha c g$-closed set of $X$, then $\mathrm{f}(\mathrm{A})$ is $\alpha c g$-closed in $\mathrm{Y}$.

Proof : Let $\mathrm{f}(\mathrm{A}) \subseteq \mathrm{O}$ where $\mathrm{O}$ is an g-open set of $\mathrm{Y}$. Since $\mathrm{f}$ is g-continuous, $\mathrm{f}^{-1}(\mathrm{O})$ is an g-open set containing $\mathrm{A}$. Hence $\mathrm{cl}(\mathrm{A}) \subseteq \mathrm{f}^{-1}(\mathrm{O})$ as $\mathrm{A}$ is a $\alpha c \mathrm{cg}$-closed set. Since $\mathrm{f}$ is $\alpha \mathrm{cg}$ closed $\mathrm{f}(\mathrm{cl}(\mathrm{A}))$ is a $\alpha \mathrm{cg}$-closed set contained in the g-open set $\mathrm{O}$, which implies that $\mathrm{cl}(\mathrm{f}(\mathrm{cl}(\mathrm{A})) \subseteq \mathrm{O}$ and hence $\operatorname{cl}(\mathrm{f}(\mathrm{A})) \subseteq$ O. So $\mathrm{f}(\mathrm{A})$ is a acg -closed set in $\mathrm{Y}$.

Corollary : 5.9 If $\mathrm{f}: \mathrm{X} \rightarrow \mathrm{Y}$ is continuous and closed and $\mathrm{A}$ is a $\alpha c g$-closed set of $X$, then $\mathrm{f}(\mathrm{A})$ is $\alpha \mathrm{cg}$-closed in $\mathrm{Y}$.

Proof : Since every continuous map is g-continuous and every closed map is acg -closed, by above theorem the result follows.
Theorem : 5.10 If $\mathrm{f}: \mathrm{X} \rightarrow \mathrm{Y}$ is a closed map and $\mathrm{h}: \mathrm{Y} \rightarrow \mathrm{Z}$ is a $\alpha c g$-closed then $\mathrm{h}: \mathrm{Y} \rightarrow \mathrm{Z}$ is $\alpha \mathrm{cg}$-closed then $\mathrm{h}$ Of $: \mathrm{X} \rightarrow \mathrm{Z}$ is a $\alpha c g$-closed.

Proof : If $\mathrm{f}: \mathrm{X} \rightarrow \mathrm{Y}$ is a closed map and $\mathrm{h}: \mathrm{Y} \rightarrow \mathrm{Z}$ is a $\alpha \mathrm{cg}$ closed map. Let $V$ be any closed set in $X$. Since $f: X \rightarrow Y$ is closed, $f(V)$ is closed in $Y$ and since $h: Y \rightarrow Z$ is $\alpha$ cg -closed, $\mathrm{h}(\mathrm{f}(\mathrm{V}))$ is a $\alpha \mathrm{cg}$-closed set in $\mathrm{Z}$. Therefore $\mathrm{h} \mathrm{Of}: \mathrm{X} \rightarrow \mathrm{Z}$ is a acg-closed map.

Theorem : 5.11 If $\mathrm{f}: \mathrm{X} \rightarrow \mathrm{Y}$ is a $\alpha \mathrm{cg}$-closed and $\mathrm{A}$ is closed set in $X$. Then $f_{A}: A \rightarrow Y$ is $\alpha$ cg -closed.

Proof : Let $\mathrm{V}$ be closed set in $\mathrm{A}$. Then $\mathrm{V}$ is closed in $\mathrm{X}$. Therefore it is $\alpha \mathrm{cg}$ closed in $\mathrm{X}$. By Theorem 5.8, $\mathrm{f}(\mathrm{V})$ is $\alpha \mathrm{cg}$ closed. That is $f_{A}(V)=f(V)$ is $\alpha c g$-closed in . Therefore $f_{A}$ : $\mathrm{A} \rightarrow \mathrm{Y}$ is acg -closed.

The next theorem shows that normality is preserved under continuous and $\mathrm{sc}^{*} \mathrm{~g}$-closed maps.

Theorem : $\mathbf{5 . 1 2}$ If $\mathrm{f}: \mathrm{X} \rightarrow \mathrm{Y}$ is a continuous, $\alpha \mathrm{cg}$-closed map from a normal space $\mathrm{X}$ onto a space $\mathrm{Y}$, then $\mathrm{Y}$ is normal.

Proof : Let A, B be disjoint closed set $Y$. Then $\mathrm{f}^{-1}(\mathrm{~A}), \mathrm{f}^{-1}(\mathrm{~B})$ are disjoint closed sets of $\mathrm{X}$. Since $\mathrm{X}$ is normal, there are disjoint open sets $\mathrm{U}, \mathrm{V}$ in $\mathrm{X}$ such that $\mathrm{f}^{-1}(\mathrm{~A}) \subseteq \mathrm{U}$ and $\mathrm{f}^{-1}(\mathrm{~B})$ $\subseteq \mathrm{V}$. By Theorem 5.7, and since $\mathrm{f}$ is acg -closed, there are acg -closed sets $\mathrm{G}, \mathrm{H}$ in $\mathrm{Y}$ such that $\mathrm{A} \subseteq \mathrm{G}$,

$\mathrm{B} \subseteq \mathrm{H}$ and $\mathrm{f}^{-1}(\mathrm{G}) \subseteq \mathrm{U}$ and $\mathrm{f}^{-1}(\mathrm{H}) \subseteq \mathrm{V}$. Since $\mathrm{U}, \mathrm{V}$ are disjoint, $\operatorname{int}(\mathrm{G})$ and $\operatorname{int}(\mathrm{H})$ are disjoint open sets. Since $\mathrm{G}$ is acg -open, $\mathrm{A}$ is closed and $\mathrm{A} \subseteq \mathrm{G} \Rightarrow \mathrm{A} \subseteq \operatorname{int}(\mathrm{G})$. Similarly $\mathrm{B} \subseteq \operatorname{int}(\mathrm{H})$. Hence $\mathrm{Y}$ is normal.

\section{CONCLUSION}

In this paper we have introduced acg-closed sets which is the weaker form of closed sets in topological spaces.And studied about the continuity and closed and open maps to the set. Some of the properties regarding these sets are discussed.

\section{REFERENCES}

[1] Levine, N., Semi-open sets and semi-continuity in topological spaces, Amer.Math.Monthly,70(1963),36-41.

[2] Levine, N., Generalized closed sets in topology, Rend. Circ. Mat. Palermo, 19(1970),89-96.

[3] Maki., Devi, R., and Balachandran, K., Generalized $\alpha$ closed sets in topology, Bull. Fukuoka Univ. Ed. Part III, 42(1993), 13-21.

[4] Hatir, E., Noiri, T., and Yuksel, S., A decomposition of continuity, ActaMath. Hungar.,70(1996),145-150.

[5] Rajamani, M., Studies on decompositions of generalized continuous maps in topological spaces, Ph.D Thesis, Bharathiar University, Coimbatore,(2001).

[6] Sundaram, P., Studies on generalizations of continuous maps in topological spaces, Ph.D Thesis, Bharathiar University, Coimbatore,(1991).

[7] Sundaram, P., On C-continuous maps in topological spaces, Proc. of $82^{\text {nd }}$ session of the Indian Science Congress, Calcutta (1995),48-49. 
[8] Tong, J., On decomposition of continuity in topological spaces, ActaMath. Hungar.,54(1989),51-55.

[9] Bhattachraya and Lahiri, B.K., Semi-generalized closed sets in topology, Indian J.Math., 29(3)375-382(1987)

[10] Nagaveni, N., Studies on Generalizations of Homeomorphisms in Topological spaces, Ph.D Thesis, Bharathiar University, Coimbatore,(1999).

[11] Andrijevic,D., Semi-preopen sets, Mat. Vesnik,38(1986),24-32.

[12] Dontchev, J., On generalizing semi-pre open sets, Mem. Fac. Sci. Kochi Univ. Ser. A. Math., 16(1995), 35-48.

[13] Biswas,N., On characterizations of semi continous functions, Atti Accad. NaZ, Lincei Rend. Cl. Sci. Fis. Mat. Natur., 48(1970),399-402

[14] Andrijevic,D., Some properties of the topology of $\alpha$-sets, Mat. Vesnik 36(1984),1-10

[15] Maki, H., Devi, R. and Balachandran, K., Associated topologies of generalized $\alpha$-closed sets and $\alpha$ generalized closed sets, Mem. Fac. Sci. Kochi univ. Ser. A, Math., 15(1994), 51-63
[16] Njastad, O., on some classes of nearly open sets, Pacific J. Math.15 (1965), 961-970.

[17] Balachandran, K., Sundaram, P., and Maki, H., On generalized continuous maps in Topological spaces, Mem. Fac. Kochi Univ. Ser. A. Math., 12(1991), 5-13.

[18] Maki, H., Devi, R., and Balachandran, K., Associated topologies of generalized $\alpha$-closed sets and $\alpha$ generalized closed sets, Mem. Fac. Sci. Kochi Univ. Ser. A. Math., 15 (1994), 51-63.

[19] Mashhour, A.S., Hasanein, I.A. and Ei-Deeb, S.N., $\alpha-$ continuous and $\alpha$ - open mapping, Acta math. Hungar. 41(1983),213-218

[20] Kavitha.A., $\alpha c g, \alpha c^{*}$ g, $\alpha c(s) g$-closed sets in Topological spaces, In the $99^{\text {th }}$ Indian Science Congress, Bhubaneswar(2012),

[21] Noiri, T., $\alpha$-continuous functions, Casopis Pest. Mat., 109(1984), 118-126.

[22] Malghan, S.R., Generalized closed maps, J. Karnataka univ. Sci., 27(1982), 82-88

[23] Biswas, N., on some mappings in topological spaces, Bull. Cal. Math. Soc., 61(1969), 127-135 